\title{
Challenges and Coping Strategies of College English Education Based on MOOC Education
}

\author{
Xin Feng \\ Teaching and Research Section of Public English, Heyuan Polytechnic, Guangdong, 517000, China
}

Keywords: MOOC era; college English; educational development; challenges; measures

Abstract: As a new attempt and bold exploration in the field of education, the MOOC education model is an innovative breakthrough in the traditional teaching mode. It effectively breaks the limitations of time and space in English classroom teaching, further promotes the stable development of education in higher education, guides its development towards innovation, and realizes the optimization and adjustment of education structure in college English. However, it also puts forward some challenges to the education of college English, and urges the reform of education of college English. Based on this, this paper analyzes and discusses the challenges faced by China's college English teaching activities in the context of MOOC education, and analyzes the countermeasures to provide a diversified teaching model for college English education.

\section{Introduction}

The MOOC Chinese name is an open online course. In 2011, it was proposed and reformed by professors at Stanford University. In 2014, the National University of Singapore and the American company Coursera reached an agreement to launch an online course in quantum physics and classical music creation. MOOC is an innovative attempt of the university education model. Through online education courses with open characteristics, students are provided with better teaching resources to improve students' learning quality and achieve university subject education. Maximizing, from this perspective, the MOOC education model is an extension and extension of the traditional education approach of the university. The MOOC education model has three characteristics: diversification of educational resources, simplification of curriculum learning, broadening of educational objects, and autonomy of curriculum participation. It can be seen that the MOOC education model is closely related to the background of the current big data era, and it has also injected a new level of impact on college English education ${ }^{[1]}$.

\section{MOOC brings challenges to Chinese college English teaching}

\subsection{MOOC sets off a battle for Chinese language education among Chinese universities and global universities}

MOOC breaks the limits of time and space, and the mode of operation continues to mature, which will soon pose a source of threat to our universities. Some scholars have asserted that MOOC 
may make most of the universities with poor teaching quality disappear. Imagine that if students can get to the top universities in the world without sitting at the computer, and complete the study according to their own characteristics, and learn from the society, then the traditional ordinary university will not exist. Now, the courses on the MOOC platform are not only produced by famous teachers, but most of the courses are free. This also weakens the competitiveness of ordinary university teachers. Figure 1 is a graph showing the increase in the amount of users on the MOOC platform.

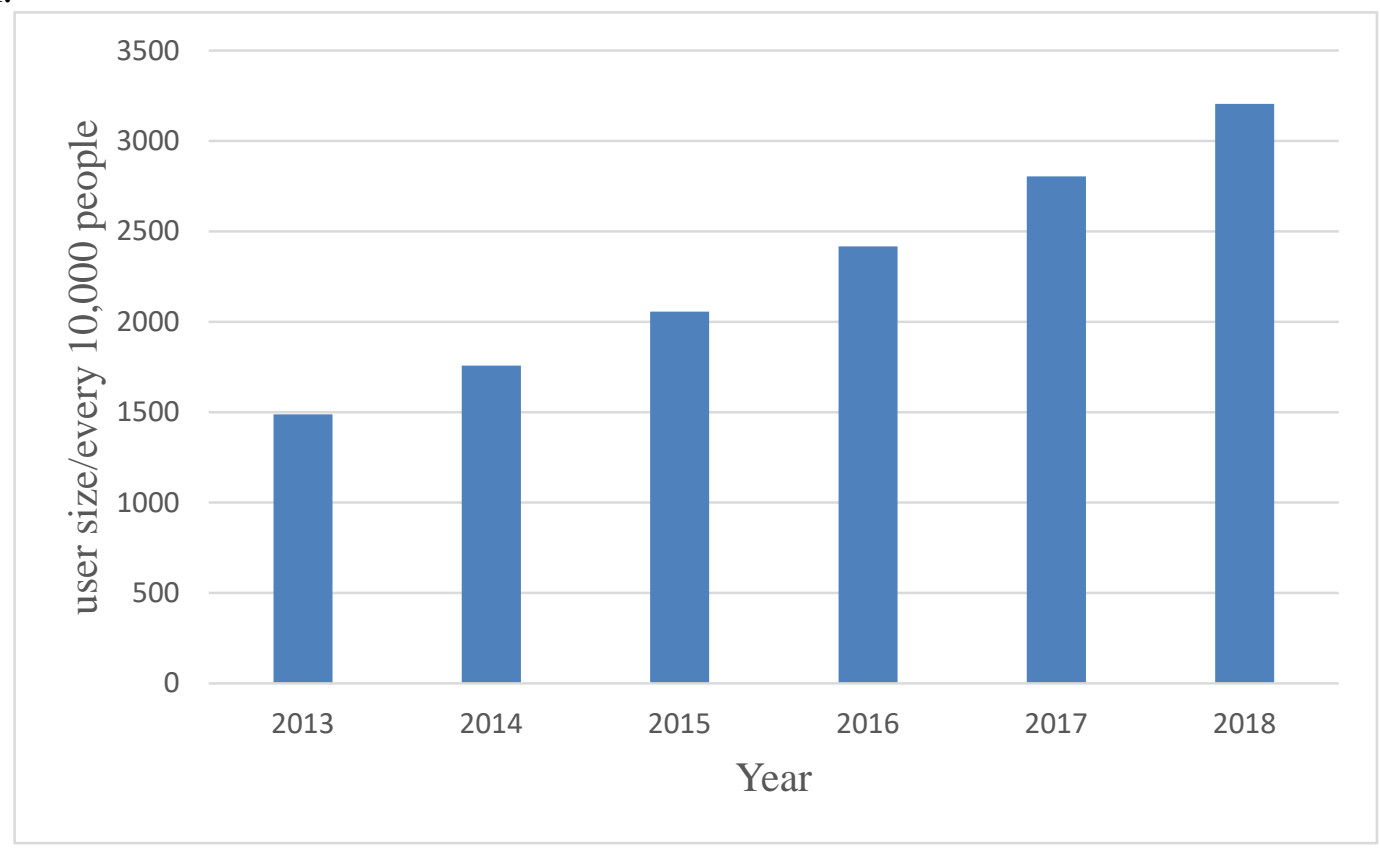

Figure 1 User scale of MOOC education in China in 2013-2018

\subsection{Challenges in the management of college English teaching}

MOOC is a new educational model intertwined with traditional educational models. It brings many new educational concepts and teaching advantages, and it will inevitably bring many problems to be solved. For example, it will cause a lot of trouble in teaching management. If thousands of students from different regions take English training courses at several different universities, and even some courses may be language courses at a university in other countries, the management of credits, academic records and test scores of these students will become one. problem. How to coordinate the student management system of universities around the world will test the wisdom of managers and system designers ${ }^{[2]}$.

\subsection{Challenges faced by college students in learning English courses under the MOOC platform}

English vocabulary is an important pillar supporting Chinese college students' acceptance of international education. College students should strive to improve their English vocabulary, especially in academic English and professional English, so that they can complete the study of various courses taught in English by native language teachers in MOOC. However, the lack of English vocabulary is a shortcoming of many Chinese college students, which will affect their learning at MOOC. At the same time, the relative weakness of Chinese college students' English listening will also affect their learning at MOOC. 


\section{Chinese University English Education Strategies for dealing with MOOC}

\subsection{Timely formulate strategies and solutions for coping with the global source of college students}

MOOC is not only a challenge to traditional Chinese English education, but also a turning point in changing many of the drawbacks of Chinese college English education. Chinese college English teachers should have a clear understanding of the trend of internationalization of college English education. When the walls of the university collapse, the flow of students will inevitably occur. When the original source of a university is lost. Chinese college English teachers can only design better, more distinctive and more practical courses and retain students with more detailed and more personalized after-school services. They can also consider developing Chinese-speaking and Chinese culture. Related courses, such as "China Tourism", "China on the Tip of the tongue", "Chinese Martial Arts", "Chinese Medicine" and "Chinese Traditional Culture", etc., to attract foreign students, and to fight against the students. In addition, there is also a huge space for Chinese college English teachers to exert their potential in the education of foreign students.

\subsection{Rapidly improve teachers' modern educational technology}

The internationalization and popularization of higher education is a typical feature of MOOC, and people can receive higher education in any place with network connection conditions. Figure 2 shows the MOOC education model. Under the MOOC era, the number of college students is bound to increase significantly. Chinese college English teachers must use computer technology to achieve teaching and management tasks, especially using computer software to quickly generate test questions, edit teaching audio and video, publish and correct electronic versions of the work on the network, and track student progress. The analysis of learning effects, statistics and assessments, and the communication and communication skills of students on the Internet are particularly important. Learning to use artificial intelligence teaching system to reduce workload and improve teaching efficiency and teaching quality is one of the key skills that Chinese college English teachers should master as soon as possible ${ }^{[3]}$.

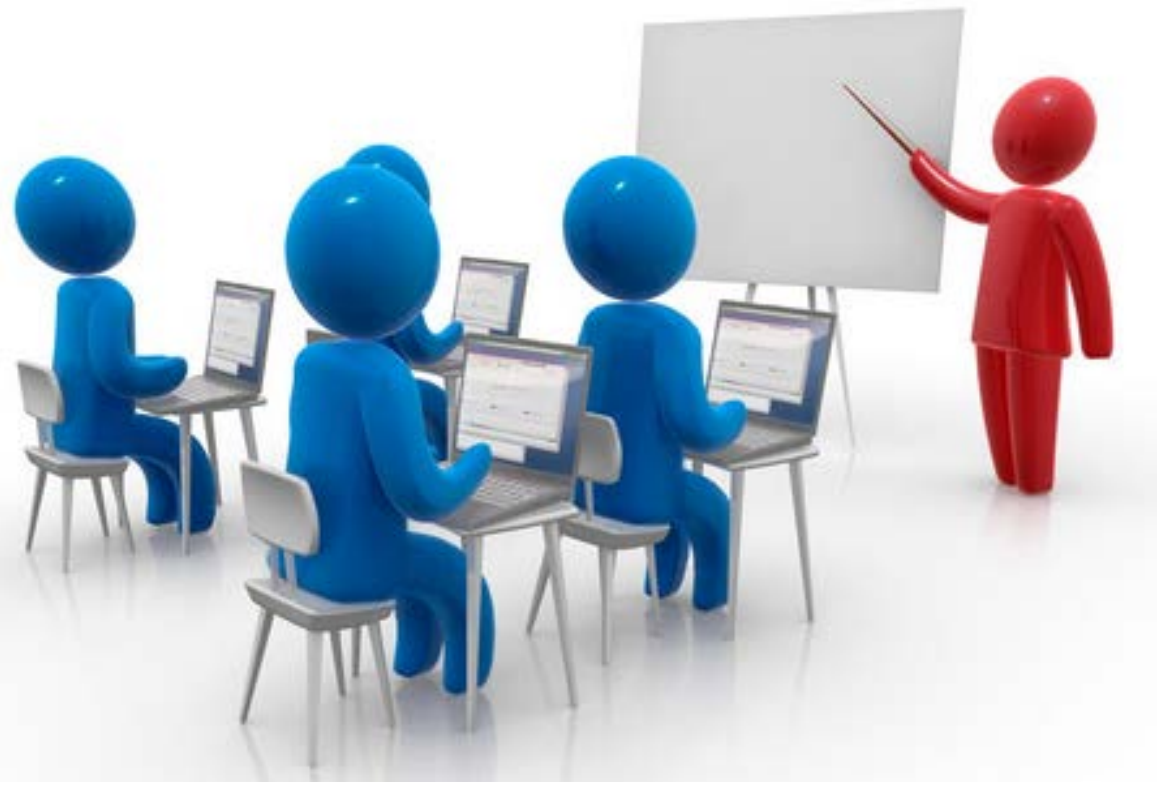

Figure 2 MOOC education model 


\subsection{Transforming the concept of education management}

Due to the large population and the scarcity of higher education resources, Chinese university management has never had to consider the issue of student resources. The college entrance examination is still a major event that determines the fate of life. However, when the MOOC brings changes to the way of education, when the trend of internationalization of higher education is about to come, a contest of teaching quality, competition for students, and competition between hard and soft power among higher education institutions may be difficult to avoid. In fact, hundreds of prestigious universities around the world have already kicked off the academic super-hegemony of the survival of the fittest at MOOC. Decision makers and managers of Chinese universities, especially decision makers and managers of college English education, should quickly realize the transformation of management concepts. Abandoning the college English education concept for the purpose of examination, the university English education will be developed in a more practical and professional direction. College English teachers should strengthen their training in modern educational skills. Only by greatly improving the ability of college English teachers to operate on more complex and complete computer systems, can Chinese colleges' English education adapt to future digital The teaching needs of the times ${ }^{[4]}$.

\subsection{Students should lay a good foundation for the English foundation of higher education internationalization}

Chinese college students who plan to take interdisciplinary courses in some foreign universities must consciously accumulate English vocabulary in relevant majors, understand the common expressions in professional language and strengthen reading on professional materials, so that they can better integrate into higher education. The trend of internationalization, through the use of English as a tool to master other professional knowledge and skills, to form a distinctive core competitiveness. In addition to the accumulation of English vocabulary and the enhancement of reading of professional English literature, English majors need to train more English listening skills in order to successfully complete the course on MOOC. In addition, Chinese college students should also improve their self-learning ability and self-control ability, and eliminate the influence of bad information on the network in order to successfully complete the learning objectives on MOOC $^{[5]}$.

\section{Conclusions}

To sum up, entered the new period, our country has realized the good development, and under the age of MOOC college English education opportunities and challenges coexist, the college English education workers should firmly seize the MOOC teaching mode of development opportunity, for its challenge to college English education put forward formulate corresponding measures, and realize the stable development of the college English education.

\section{Acknowledgement}

Student oriented oral English formative assessment in higher vocational colleges.

\section{References}

[1] Zhou Jialin. Opportunities, Challenges and Coping Strategies of College English Education in China under the MOOC Era[J]. Journal of Zhaoqing University, 2014, 35(6): 82-87.

[2] Ying Chunyan. The Enlightenment of College English Teaching Based on MOOC to the Publishing of Higher 
Education Textbooks[J]. Science Technology and Publishing, 2015(9):111-116.

[3] Wu Qingyu. Research on College English English Flipping Classroom Teaching Model Based on MOOC[J]. Northern Literature: Xia, 2015(8):192-192.

[4] Xue Wei. Research on Postgraduate Education Reform Based on MOOC[J]. China Educational Technique and Equipment, 2017(10).

[5] Su Xiangfeng, Han Xue, Jiang Kun. Research on the Reform Strategy of College Classroom Teaching Based on MOOC[J]. Digital World, 2018(3). 